\title{
Increased expression of the prolactin receptor is associated with malignant laryngeal tumors
}

\author{
LUIS R. GONZÁLEZ-LUCANO ${ }^{1}$, JOSÉ F. MUÑOZ-VALLE² ${ }^{2}$, RAFAEL ASCENCIO-CEDILLO ${ }^{1}$, \\ JOSÉ A. DOMÍNGUEZ-ROSALES ${ }^{3}$, GONZALO LÓPEZ-RINCÓN ${ }^{4}$, SUSANA DEL TORO-ARREOLA ${ }^{1}$, \\ MIRIAM BUENO-TOPETE ${ }^{2}$, ADRIÁN DANERI-NAVARRO ${ }^{1}$, \\ CIRO ESTRADA-CHÁ VEZ ${ }^{4}$ and ANA L. PEREIRA-SUÁREZ ${ }^{1}$
}

\begin{abstract}
Departments of ${ }^{1}$ Physiology, and ${ }^{2}$ Molecular Biology and Genomics; ${ }^{3}$ Institute of Chronic Degenerative Diseases, University Center for Health Sciences, University of Guadalajara; ${ }^{4}$ Unit of Medical and Pharmaceutical Biotechnology, Center for Research and Assistance in Technology and Design of Jalisco, Guadalajara, Jalisco, Mexico
\end{abstract}

Received August 25, 2011; Accepted October 14, 2011

DOI: $10.3892 /$ etm.2012.464

\begin{abstract}
The altered expression of the prolactin receptor (PRLR) has been associated with the development of various types of cancer, particularly breast, prostate and endometrial cancer. However, in laryngeal tumors, the expression of PRLR has not yet been documented. The aim of this study was to determine the expression and localization of PRLR in laryngeal cancer (LC) in comparison with recurrent respiratory papillomatosis (RRP). PRLR expression was analyzed in 48 paraffin-embedded tissues (18 RRP and 30 laryngeal cancer tissues) by immunoperoxidase staining. Furthermore, PRLR expression was evaluated in ten samples from each group by Western blot analysis and quantitative real-time PCR. PRLR was observed in all laryngeal tumors at different intensities. PRLR overexpression was significantly associated $(\mathrm{P}<0.005)$ with LC. The staining pattern was homogeneous, mainly cytoplasmic, and confined to the tumor area. We found increased expression of different isoforms in LC in comparison with RRP. Our results suggest a possible role of PRL/PRLR in the development of LC. PRLR may be useful as a target for further investigations in laryngeal tissues.
\end{abstract}

\section{Introduction}

The larynx is a mucosal organ positioned at the divergence of the respiratory and digestive tracts. Laryngeal cancer (LC) is a very frequent malignant neoplasm of the head and neck region. It is responsible for approximately 159,000 new cases and

Correspondence to: Dr Ana Laura Pereira-Suárez, Department of Physiology, University Center for Health Sciences, University of Guadalajara, Sierra Mojada No 950, Colonia Independencia, Guadalajara, Jalisco C.P. 44340, Mexico

E-mail: analauraps@hotmail.com

Key words: prolactin receptor, laryngeal cancer, recurrent respiratory papillomatosis, proliferation, biomarker
90,000 mortalities every year (1). Recurrent respiratory papillomatosis (RRP) is the most frequent benign laryngeal neoplasm, and is mainly caused by human papillomavirus types 6 and 11 . Patients with RRP have exophytic airway lesions that may progress to respiratory insufficiency. It is estimated that between 1,500 and 2,500 new cases of RRP occur in the United States each year, and 3,870 cases are expected in the Mexican infantile population $(2,3)$. Smoking is considered to be the main trigger factor of LC, and in association with alcohol consumption the risk of cancer increases (4). LC is characterized by high proliferative potential mediated by an increase in the expressions of cyclin D1 and Ki67 (5). However, the mechanisms underlying the proliferation of this form of cancer are not yet fully understood. Alterations in the expression of prolactin (PRL) and certain signaling intermediate levels can contribute to the development and progression of certain types of cancer, particularly in hormone-dependent organs (e.g., breast, endometrium, prostate), but most likely at other primary sites as well (6-8). The diverse activities of PRL are mediated by its receptor (PRLR) and it involves the activation of a number of signaling pathways including Jak2-STAT (9), PI3K (10) and MAPK $(11,12)$. There are multiple isoforms of the PRLR in humans, the long form of 70-90 kDa (LF), intermediate form of 40-50 kDa (IF), and two short forms of 42-56 kDa (SF1a) and 32-42 kDa (SF1b) which are produced by alternative splicing (13). To date, there have been no studies focusing on the analysis of PRL or PRLR expression in laryngeal tumor lesions. The objective of this study was to determine the PRLR expression and its association in RRP and LC in order to identify the possible participation of PRLR in laryngeal tumors.

\section{Materials and methods}

Patients and tissue samples. We evaluated 48 tissue samples from male patients obtained from the Pathology Department at the Civil Hospital of Guadalajara 'Fray Antonio Alcalde', and the Departments of Oncology and Pathology at the Mexican Social Security Institute, Guadalajara, Mexico. Tissues were fixed in $4 \%$ formalin and embedded in paraffin. All samples 
were evaluated and characterized by an experienced pathologist. A total of $30 \mathrm{LC}$ samples from patients aged 44-81 years (mean age, 60.1 years) and 18 samples of RRP from patients aged 3-58 years (mean age, 8.2 years) were included for analysis by immunohistochemistry. A total of 20 samples were included in the PRL/PRLR Western blot analysis and quantitative real-time PCR assays. All samples were obtained in accordance with the Guidelines of the Mexican Official Standard (Norma Oficial Mexicana, NOM) and the World Medical Association Declaration of Helsinki.

Immunohistochemical staining. Serial sections from the formalin-fixed paraffin-embedded blocks were used for the detection of PRLR by immunohistochemistry. Sections were deparaffinized by successive immersions in $100 \%$ xylene, $100 \%$ ethanol, $96 \%$ ethanol and $70 \%$ ethanol for $10,10,5$ and $5 \mathrm{~min}$, respectively. Endogenous peroxidase activity was inactivated with peroxidase blocking reagent (S2001; Dako, Glostrup, Denmark) for $10 \mathrm{~min}$. Antigen retrieval was achieved by exposure to $10 \mathrm{mM}$ citrate buffer ( $\mathrm{pH}$ 6.0) and autoclaving at $121^{\circ} \mathrm{C}$ for $15 \mathrm{~min}$. Following blockade with $50 \mu 1$ of $1 \% \mathrm{BSA}$ (Sigma, USA) in TBST buffer ( $50 \mathrm{mM}$ Tris- $\mathrm{HCl}, 300 \mathrm{mM} \mathrm{NaCl}$, $0.1 \%$ Tween-20) for $5 \mathrm{~min}$ at room temperature, the sections were incubated overnight with $40 \mu \mathrm{l}$ of anti-PRLR primary antibody (clone H-300; Santa Cruz Biotechnology, Santa Cruz, CA, USA) prediluted 1:100 in TBST at $4^{\circ} \mathrm{C}$ in a humidified chamber. The sections were then washed with TBST and incubated with one drop of secondary antibody conjugated with HRP (K4061; Dako) for $60 \mathrm{~min}$ at room temperature. Following washing, the sections were incubated with one drop of chromogenic 3,3'-diaminobenzidine (DAB) substrate (K3468; Dako) for $15 \mathrm{~min}$ at room temperature. Sections were counterstained with Mayer's hematoxylin and mounted on a hydrosoluble medium (VectaMount AQ). Additionally, all sections were developed in parallel with a negative control reaction omitting the primary antibody. No signal was observed.

Western blot analysis. Proteins were extracted from tissue samples with $300 \mu$ l of RIPA buffer [ $50 \mathrm{mM}$ Tris, $150 \mathrm{mM} \mathrm{NaCl}$, $1 \%$ NP40, $0.5 \%$ sodium deoxycholate and $0.1 \%$ sodium dodecyl sulfate (SDS)], protease inhibitors (pestatin, leupeptin, aprotinin, quimostatin, antipain and PMSF) and phosphatase inhibitors $\left(\mathrm{Na}_{3} \mathrm{VO}_{4}\right.$, and NAF) were added, and were clarified by centrifugation at $4^{\circ} \mathrm{C}$ for $20 \mathrm{~min}$. Protein concentration was determined by the bicinchoninic acid method (BCA Protein Assay Reagent; Pierce, Rockford, IL, USA). Total protein $(40 \mu \mathrm{g})$ was mixed with loading buffer, electrophoresed on 7.5-10\% SDS-polyacylamide gels and transferred to a polyvinylidene difluoride membrane (Bio-Rad, CA, USA). Non-specific binding was blocked with $5 \%$ milk and $1 \%$ bovine serum albumin solution. Subsequently, the membranes were incubated with $2 \mu \mathrm{g} / \mathrm{ml}$ polyclonal PRL or PRLR antibody (clone H-300; Santa Cruz Biotechnology) at $4^{\circ} \mathrm{C}$ overnight. HRP-conjugated anti-rabbit secondary antibody was used to reveal the immune detection and blots were developed with a chemiluminescence system (Millipore, Billerica, MA. USA). As an internal control to confirm that similar amounts of protein were loaded for each lane, actin levels were determined using a monoclonal anti-actin IgG (Chemicon International, Temecula, CA, USA) at 1:10,000 and revealed with anti-mouse IgG peroxidase (Santa Cruz Biotechnology).
Table I. Prolactin receptor expression in laryngeal cancer and recurrent respiratory papillomatosis by immunohistochemistry.

\begin{tabular}{lcc}
\hline $\begin{array}{l}\text { PRLR } \\
\text { immunohistochemistry }\end{array}$ & $\begin{array}{c}\text { Laryngeal cancer } \\
\mathrm{n}(\%)\end{array}$ & $\begin{array}{c}\mathrm{RRP}^{\mathrm{a}} \\
\mathrm{n}(\%)\end{array}$ \\
\hline Low & $7(23.3)$ & $11(61.1)$ \\
Moderate & $17(56.7)$ & $7(38.9)$ \\
Intense & $6(20)$ & $0(0)$ \\
Total & $30(100)$ & $18(100)$ \\
\hline
\end{tabular}

${ }^{\mathrm{a}} \mathrm{P}<0.05$, significative value.

Microscopic analysis. The immunostained slides were evaluated independently by two of the authors. When disagreements occurred between the two observers they were resolved using a double-headed microscope. The staining intensity was evaluated semiquantitatively as follows: negative (no immunolabeling), low, moderate and intense. Negative controls included omission of the primary antibody.

Quantitative real-time PCR. RNA was isolated from laryngeal tissues from various groups of patients with TRIzol reagent (Invitrogen, Carlsbad, CA, USA). Retrotranscription using $2 \mu \mathrm{g}$ of total RNA was achieved using M-MLV reverse transcriptase (Invitrogen). Then, $2 \mu 1$ of cDNAs were subjected to real-time PCR using a Rotor-Gene Thermocycler under the following conditions: $2 \mathrm{~min}$ at $50^{\circ} \mathrm{C}, 10 \mathrm{~min}$ at $95^{\circ} \mathrm{C}$, and 45 cycles of $15 \mathrm{sec}$ at $95^{\circ} \mathrm{C}$ and $1 \mathrm{~min}$ at $60^{\circ} \mathrm{C}$. The reaction mixture included a $200 \mathrm{nM}$ final concentration of both forward (5'agaccatggatactggagta-3') and reverse (5'ggaaagatgcaggtca ccat-3') PRLR-specific primers, and a $100 \mathrm{nM}$ final concentration of the PRLR-specific probe (5'-tctgctgtcatctgtttgatta-3') labeled with FAM reporter fluorescent dye designed for amplification of all three isoforms of PRLR (14). Gene amplification was normalized against $18 \mathrm{~S}$ expression with the specific probe, human Hs03928985_g1 (Applied Biosystems Hammonton, NJ, USA), labeled with FAM. Relative quantification using the $2^{-\triangle \Delta C T}$ method was then carried out using the comparison to the control groups as an internal calibrator $(15,16)$.

Statistical analysis. Data were either analyzed by the Student's t-test or one-way ANOVA to determine statistical differences between the groups using Microsoft Excel and SPSS version 18.0 software (SPSS Inc., Chicago, IL, USA). Results were considered to be statistically significant at $\mathrm{P}<0.05$.

\section{Results}

Detection and localization of PRLR in the laryngeal tumors by immunohistochemistry and Western blot analysis. PRLR expression was analyzed in 48 laryngeal tissues from males by the immunoperoxidase method. Immunolabeling of PRLR was observed in all malignant tumors; in 23 (76.7\%) cases the immunoreactivity was moderate to intense and low in $7(23.3 \%)$ cases. The staining pattern was confined to the tumor cells, and was mostly cytoplasmic. Cells adjacent to the tumor 


\section{Recurrent respiratory papillomatosis}
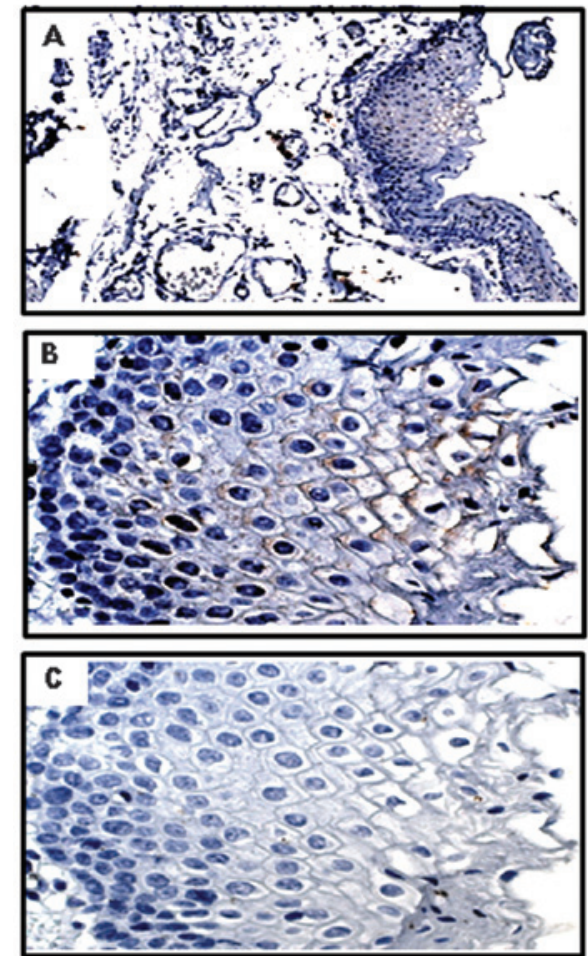

Laryngeal cancer
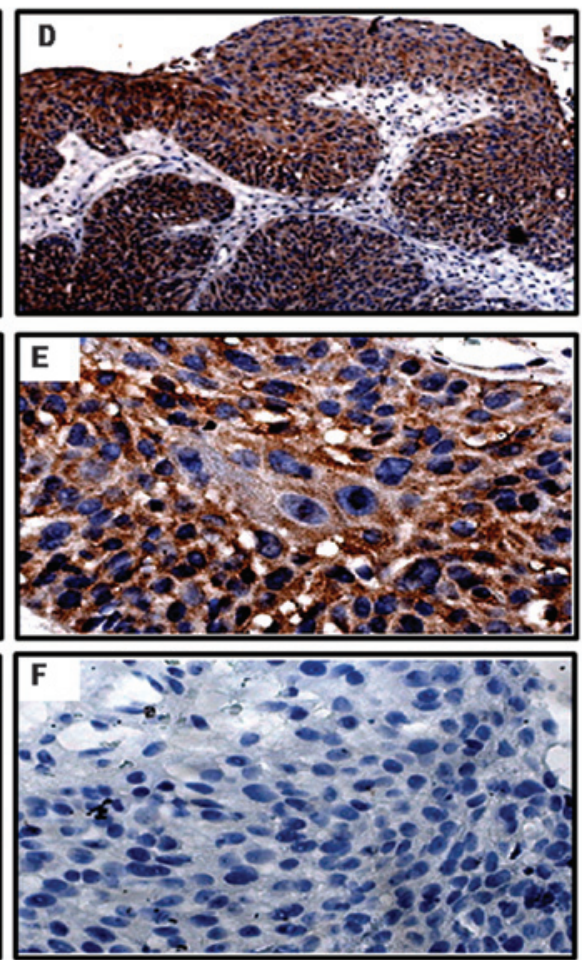

Figure 1.PRLR protein expression in laryngeal tissues analyzed by immunohistochemical staining using a polyclonal anti-PRLR antibody in paraffin-embedded tissue sections. DAB was used as a chromogen and Mayer's hematoxylin as a counterstain. (A-C) Recurrent respiratory papillomatosis, (D-F) larynx cancer. (A-C) Magnification, x10; (D-F) magnification, x40; (C and F) magnification, x40; specimens used as the negative control without primary antibody. PRLR, prolactin receptor; DAB, 3,3'-diaminobenzidine.

showed very low PRLR expression. The PRLR staining level was significantly higher in the LC than RRP tissues $(\mathrm{P}<0.005)$; in $7(38.9 \%)$ RRP cases the staining was moderate and low in $11(61.1 \%)$ cases. We did not observe intense expression of PRLR in any RRP samples. A representative example of each group is shown in Fig. 1. Table I presents a semiquantitative estimation of the immunolabeling studies of laryngeal tissues with anti-PRLR antibodies.

To evaluate whether there are different PRLR forms in RRP and LC samples, we determined the PRLR expression by Western blot analysis in ten samples from each group.

In order to demonstrate the reactivity of the anti-PRLR antibody by Western blot analysis, we analyzed total proteins extracted from the MFC7 breast cancer cell line, which is known to express a high amount of PRLR. The presence of four different PRLR isoforms in the MCF7 breast cancer cellline of approximately 90-110, 65 and 42-45 kDa associated with long, intermediate, and short isoforms were observed. The expression levels of the PRLR isoforms were different for each sample group (LC and RRP) analyzed. In RRP, one PRLR isoform of $42 \mathrm{kDa}$ was moderately expressed. However, the LC samples showed more prominent bands of 42-45 $\mathrm{kDa}$ than the RRP samples. Also, strong bands of $65 \mathrm{kDa}$, as well as weak bands of approximately $100 \mathrm{kDa}$, were detected in all cancer samples (Fig. 2).

PRLR MRNA expression by quantitative real-time reverse transcriptase PCR (qRT-PCR) in laryngeal tissues. qRT-PCR

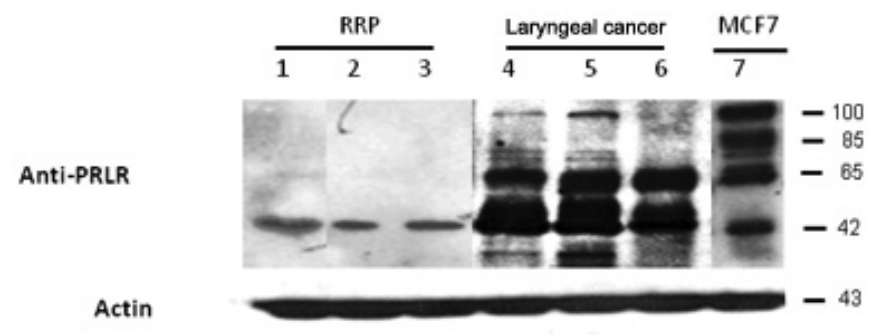

Figure 2. Western blot analysis of laryngeal tissues with anti-PRLR antibody. Lanes 1-3, recurrent respiratory papillomatosis; lanes 4-6, laryngeal cancer tissues; lane 7, the breast cancer cell line, MCF7. Actin was used as the loading control. PRLR, prolactin receptor.

was performed in ten laryngeal tissue samples (five LC and five RRP samples). Gene amplification was normalized against $18 \mathrm{~S}$ expression with the specific probe. We labeled the expression of PRLR mRNA in all these samples. The levels of PRLR mRNA in the LC samples were higher than those in the RRP samples (Fig. 3). LC results showed a ten-fold $(10.79 \pm 1.27)$ increase with respect to RRP with a significance value of $\mathrm{P}<0.005$.

\section{Discussion}

To date it is known that the amount of PRLR on the cell surface directs both the intensity and length of PRL signals in cells and 


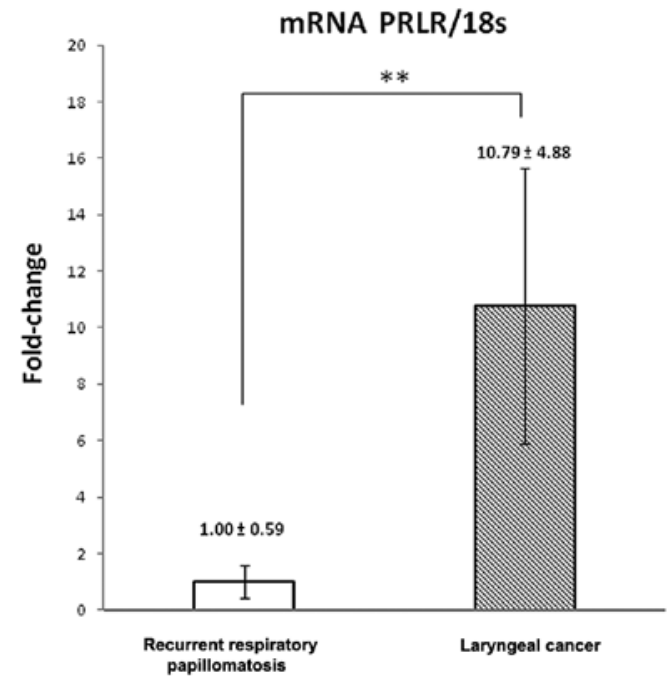

Figure 3. Comparison of relative PRLR mRNA levels of recurrent respiratory papillomatosis and laryngeal cancer tissues, normalized to $1 \mu \mathrm{g} / \mu \mathrm{l}$ of total RNA. Y-axis, fold difference. ${ }^{* *} \mathrm{P}<0.005$. PRLR, prolactin receptor; mRNA, messenger RNA.

therefore cellular response to PRL. Thus, alterations in PRLR levels may lead to aberrant downstream signaling resulting in the disruption of cellular homeostasis.

The tumorigenic potency of PRL based on circulating PRL levels in various types of human tumors has been controversial. For example, epidemiological studies performed during the 80's and 90 's were unable to reach unified conclusions regarding any correlations between circulating PRL levels and breast cancer (17). With regard to other types of cancer, the data are much sparser than for breast cancer. For example, studies on prostate cancer and head and neck cancer concluded that there was no correlation between PRL levels and cancer risk $(18,19)$. However, Yurkovetsky et al showed that PRL was the strongest discriminative biomarker for endometrial cancer (20).

Over the last decade, a number of experimental and clinical studies have shown that PRLR is widely overexpressed in tumors at a local level, including breast, colorectal, prostate and head and neck cancer (7,21-23). However, to date, the role of PRL/PRLR in laryngeal tumors remains largely unknown. Our study is the first to show the expression of PRLR in RRP and LC at RNA and protein levels. Notably, a strong immunoreactivity was significantly associated only with malignant laryngeal tumors, whereas only $38.9 \%$ of RRP samples showed a moderate labeling. Moreover, immunohistochemistry results of PRLR expression were consistent with the finding obtained by Western blot analysis and real-time PCR. In a recent assay, Bauernhofer et al reported that PRLR is widely expressed in squamous cell cancer of the head and neck (SCCHN) tissues; however, they did not explain which specific organs were involved (22). SCCHN includes cancer of the oral cavity, pharynx and larynx. It is crucial to note that all samples included in our study were obtained from male patients, in whom there is no change in PRL levels in pre- and post-reproductive stages. However, the molecular mechanism by which PRL/PRLR is involved in laryngeal tumors remains unknown. It has been reported in other tissues that this peptide hormone up-regulates the expression of a set of genes involved in cell proliferation or differentiation (24). The proteolytic degradation of PRLR is usually induced through ubiquitination (25). However, in this study, in agreement with others, the PRLR showed a high correlation with the malignant phenotype of different tissues. Recently, it has been demonstrated that the stabilization of PRLR in breast cancer by decreasing the activity of GSK3b, is a result of the constitutive activation of a Ras-dependent oncogenic pathway (26). The accumulation of PRLR in the cytoplasm and its consequent translocation to the nucleus may explain our observations. Additionally, other malignant processes directed by non-ubiquitinated proteins may be operating (27).

Currently, it is known that PRL carries out its activity by at least six recognized PRLR isoforms. These various PRLR isoforms exhibit different signaling properties. The long PRLR isoform is capable of activating virtually all of the signaling pathways. By contrast, since the short PRLR isoform is not tyrosine phosphorylated (which prevents its interaction directly with SH2-containing proteins), Stat factors are not activated through this isoform (28). In this study, we found a number of isoforms of PRLR expressed in laryngeal tissues, whereas in RRP, only a weak short band of approximately $42 \mathrm{kDa}$ was expressed. Markedly, the LC samples strongly expressed three PRLR isoforms of 42,45 and $65 \mathrm{kDa}$ and also expressed a weak band of $100 \mathrm{kDa}$, suggesting that a signaling pathway may be up-regulated. In this regard, the abundant isoform expression of PRLR may indicate the progression toward cancer. To confirm this hypothesis, further experiments are necessary to verify the different isoforms expressed in our samples. These should include other methodologies using specific antibodies or primers for PRLR, as was recently carried out in a study on breast cancer (29).

In conclusion, the overexpression of PRLR suggests that it may be a tumor biomarker, particularly in malignant laryngeal tumors.

\section{Acknowledgements}

This study was financed by grants from SEP-CONACYT (79709) and PROMEP UDG-PTC-605 both to A.L.P.-S.

\section{References}

1. Parkin DM, Bray F, Ferlay J and Pisani P: Global cancer statistics, 2002. CA Cancer J Clin 55: 74-108, 2005.

2. Derkay CS: Recurrent respiratory papillomatosis.Laryngoscope 111: 57-69, 2001.

3. Penaloza-Plascencia M, Montoya-Fuentes H,Flores-Martinez SE, Fierro-Velasco FJ, Penaloza-Gonzalez JM and Sanchez-Corona J: Molecular identification of 7 human papillomavirus types in recurrent respiratory papillomatosis. Arch Otolaryngol Head Neck Surg 126: 1119-1123, 2000.

4. Hashibe M, Boffetta P, Zaridze D, et al: Contribution of tobacco and alcohol to the high rates of squamous cell carcinoma of the supraglottis and glottis in Central Europe. Am J Epidemiol 165: 814-820, 2007.

5. Cordes C, Munzel AK, Rudolph P, Hoffmann M, Leuschner I and Gottschlich S: Immunohistochemical staining of Ki-67 using the monoclonal antibody $\mathrm{Ki}$-s11 is a prognostic indicator for laryngeal squamous cell carcinoma. Anticancer Res 29: 1459-1465, 2009.

6. McHale K, Tomaszewski JE, Puthiyaveettil R, Livolsi VA and Clevenger CV: Altered expression of prolactin receptor-associated signaling proteins in human breast carcinoma. Mod Pathol 21: 565-571, 2008. 
7. Leav I, Merk FB, Lee KF, et al: Prolactin receptor expression in the developing human prostate and in hyperplastic, dysplastic, and neoplastic lesions. Am J Pathol 154: 863-870, 1999.

8. Levina VV, Nolen B, Su Y, et al: Biological significance of prolactin in gynecologic cancers. Cancer Res 69: 5226-5233, 2009.

9. Rui H, Kirken RA and Farrar WL: Activation of receptor-associated tyrosine kinase JAK2 by prolactin. J Biol Chem 269: 5364-5368, 1994.

10. Al-Sakkaf KA, Dobson PR and Brown BL: Prolactin induced tyrosine phosphorylation of p59fyn may mediate phosphatidylinositol 3-kinase activation in Nb2 cells. J Mol Endocrinol 19: 347-350, 1997.

11. Das R and Vonderhaar BK: Activation of raf-1, MEK, and MAP kinase in prolactin responsive mammary cells. Breast Cancer Res Treat 40: 141-149, 1996.

12. Nohara A, Ohmichi M, Koike K, et al: Prolactin stimulates mitogen-activated protein kinase in human leiomyoma cells Biochem Biophys Res Commun 238: 473-477, 1997.

13. Ben-Jonathan N, Lapensee CR and Lapensee EW: What can we learn from rodents about prolactin in humans? Endocr Rev 29 $1-41,2008$

14. Peirce SK and Chen WY: Quantification of prolactin receptor mRNA in multiple human tissues and cancer cell lines by real time RT-PCR. J Endocrinol 171: R1-R4, 2001.

15. Yuan JS, Reed A, Chen F and Stewart CN Jr: Statistical analysis of real-time PCR data. BMC Bioinformatics 7: 85, 2006.

16. Livak KJ and Schmittgen TD: Analysis of relative gene expression data using real-time quantitative PCR and the 2(-Delta Delta C(T)) method. Methods 25: 402-408, 2001

17. Tworoger SS and Hankinson SE: Prolactin and breast cancer risk. Cancer Lett 243: 160-169, 2006.

18. Stattin P, Rinaldi S, Stenman UH, et al: Plasma prolactin and prostate cancer risk: A prospective study. Int J Cancer 92: 463-465, 2001.

19. Meyer F, Samson E, Douville P, Duchesne T, Liu G and Bairati I: Serum prognostic markers in head and neck cancer. Clin Cancer Res 16: 1008-1015, 2010.
20. Yurkovetsky Z, Ta'asan S, Skates S, et al: Development of multimarker panel for early detection of endometrial cancer. High diagnostic power of prolactin. Gynecol Oncol 107: 58-65, 2007.

21. Harbaum L, Pollheimer MJ, Bauernhofer T, et al: Clinicopathological significance of prolactin receptor expression in colorectal carcinoma and corresponding metastases. Mod Pathol 23: 961-971, 2010.

22. Bauernhofer T, Pichler M, Wieckowski E, et al: Prolactin receptor is a negative prognostic factor in patients with squamous cell carcinoma of the head and neck. Br J Cancer 104: 1641-1648, 2011.

23. Gill S, Peston D, Vonderhaar BK and Shousha S: Expression of prolactin receptors in normal, benign, and malignant breast tissue: an immunohistological study. J Clin Pathol 54: 956-960, 2001.

24. Brockman JL, Schroeder MD and Schuler LA: PRL activates the cyclin D1 promoter via the Jak2/Stat pathway. Mol Endocrinol 16: 774-784, 2002.

25. Varghese B, Barriere H, Carbone CJ, et al: Polyubiquitination of prolactin receptor stimulates its internalization, postinternalization sorting, and degradation via the lysosomal pathway. Mol Cell Biol 28: 5275-5287, 2008.

26. Plotnikov A, Li Y, Tran TH, et al: Oncogene-mediated inhibition of glycogen synthase kinase 3 beta impairs degradation of prolactin receptor. Cancer Res 68: 1354-1361, 2008.

27. Li Y, Clevenger CV, Minkovsky N, et al: Stabilization of prolactin receptor in breast cancer cells. Oncogene 25: 1896-1902, 2006.

28. Binart N, Bachelot A and Bouilly J: Impact of prolactin receptor isoforms on reproduction. Trends Endocrinol Metab 21: 362-368, 2010.

29. Ginsburg E, Alexander S, Lieber S, et al: Characterization of ductal and lobular breast carcinomas using novel prolactin receptor isoform specific antibodies. BMC Cancer 10: 678, 2010. 